\title{
Purpose Driven Internet Use and Its Impact on Academic Performance of College Students
}

\author{
Aida W. Waweru (Corresponding Author) \\ Department of Library and Information Science \\ School of Education, Kenyatta University \\ Martin Gichugu (Ph.D) \\ Department of Library and Information Science \\ School of Education, Kenyatta University
}

Received: October 29, 2021 Accepted: November 26, 2021 Published: November 27, 2021

doi:10.5296/jet.v9i1.19263

URL: https://doi.org/10.5296/jet.v9i1.19263

\begin{abstract}
The purpose of this study was to determine how students in Middle-Level Colleges use the internet, with a special focus on the Nairobi Institute of Business Studies (NIBS). The study was conducted using a descriptive research approach. The student population was determined using a purposive sample strategy, while the stratified sampling approach was utilized to divide the population into distinct subgroups (strata) based on the eight courses that students took. Both open-ended and closed-ended questionnaires were used to collect relevant data. The questionnaire was tested for validity and reliability in a group of randomly selected students. Following data collection, descriptive statistics were used to examine pertinent data. To summarize the data and report the research findings, descriptive statistics such as percentages, frequencies, bar graphs, and pie charts were used. This research focused on the NIBS College, which has approximately 3000 regular students. A total of 138 people were sampled from the population to participate in the study. The majority of students, according to the report, use the internet for entertainment. For communication and pleasure, students utilize social networking sites like Facebook and Twitter at nearly the same rates. The respondents also stated that using the internet has expanded their access to more up-to-date educational information and has had a good impact on their academic efficiency. When compared to traditional materials, respondents found the Internet to be more informative. The respondents also said that the internet saved time and provided reliable information. To access the internet, most students possess and use smartphones (iPhones). They use the
\end{abstract}


internet in their dorms compared to other locations on campus or at home, where internet access was unreliable. The majority of students preferred Google to other Internet services. This demonstrated that students rely extensively on Google to find current and relevant information. The vast majority believed that people do not need to be trained on how to use the internet to find information. The trial-and-error method was the most prevalent strategy for obtaining relevant Internet skills. Others sought advice from their peers or took official training given by several computer colleges to learn how to utilize the internet.

Keywords: internet, students, study, access, purpose, impact

\section{Introduction}

Among the most important technical innovations of the late twentieth century is the Internet. The Internet requires a set of skills, and any country that does not allow access to its youngsters to access the internet will and is likely to lag in terms of development. The internet allows people of all ages to gain access to various activities whenever they want to (Akin-Adaeamola, 2014). Internet use is a technology that has been rapid and therefore has been ingrained in many people's everyday routines. The initial idea behind the introduction of the internet is for college students and other institutions to have a better academic experience in the mid-1990s. This is because of its potential to act as a support medium in many ways depending on how individuals use it (Ngoumandjoka, 2012). Internet access has greatly increased in the present day and is now available in different localities including homes, workplaces, travel, and learning institutions (Ellore et al., 2014).

In these times of fast social and technical development, middle-level colleges are becoming increasingly relevant globally. Siraj et al (2015) discovered in Japan that the internet is a major ICT that has resulted in a worldwide revolution in the information landscape. Students need more up-to-date skills to engage in economic knowledge, as the skills they learn are becoming more obsolete. As a result, students' academic performance might be influenced by their access to information via the internet (Akande \& Bamise, 2017). The utilization of trustworthy online resources is of increased relevance for academic study at any college that requires an academic evaluation of literature for educational purposes, which has proved to be at the heart of academic accomplishment.

Studies have shown that almost $78.1 \%$ of the US population utilizes the internet frequently, according to internet world statistics (2012). The United States is one of the top ten nations in the world on intense internet usage with 245 million people utilizing it. Students may use the internet to boost their creativity, conduct relevant research and do assignments using material from across the world and it also facilitates collaboration with the academic community (Ellore et al., 2014; Siraj et al., 2015). Yesilyurt et al (2014) stated that the performance of college students can be improved if they have a desktop and connection to the internet hence boosting their learning skills.

Access to internet services is critical for a developing country like Ghana in Sub-Saharan Africa. Updated and modern materials are nicely arranged on the internet for quick search, and it has helped pupils achieve academic success (Kumar, 2015). College students consider 
the library as a good place to study and a good source of research information, but they like using the internet as opposed to the library since the latter gives constant access to the bulk of information (Kumar, 2015). Despite the importance of internet usage to kids' academic success, it has a variety of negative consequences. Some learners use the internet for non-academic activities like gaming and social networking, causing them to miss class (Singh et al., 2013). Ngoumandjoka (2012) discovered that certain pupils in Johannesburg, South Africa, utilize the internet for recreational rather than instructional objectives, which can lead to lowered academic grades. Charting, downloading, viewing movies online, playing online games, and online buying are among the most popular non-academic activities done over the internet by some middle-level college students (Akin-Adramola, 2014). As a result, if not managed properly, the internet may be a detrimental instrument for academic success (Mami \& Hatami-Zad, 2014).

On December 11, Internet World Statistics (2012), reported that Africa accounted for only 6.2 percent of people who use the internet. However, available figures show that between the years 2000 and 2011, the number of people using the Internet in Africa increased from $4,514,400$ to $139,875,242$. In addition, mobile phone penetration increased from an estimated $1 \%$ to $50 \%$ from the year 2000 to the year 2012. In Sub-Saharan Africa, there are now over 754 million connections and over 35 mobile network carriers. Several African nations, like Tunisia, Ghana and Morocco, have mobile subscriber penetration rates above $100 \%$. According to data from Internet World Statistics, the continent's internet users increased seven times faster than the world average. The International Telecommunication Union reported that, Africa's internet penetration rate was 15.3 percent in June 2012. More individuals in Africa have adopted new forms of information transmission in the recent decade as shown in Table 1.1.

Table 1. 1. Comparison of Internet usage in Africa and the Rest of the World

\begin{tabular}{l|l|l|l|l|}
\hline Region & $\begin{array}{l}\text { Population } \% \\
\text { the world }\end{array}$ & $\begin{array}{l}\text { Penetration } \\
\text { of population }\end{array}$ & $\begin{array}{l}\% \text { of User growth } \\
(2000-2010)\end{array}$ & $\begin{array}{l}\% \text { of users in the } \\
\text { world }\end{array}$ \\
\hline $\begin{array}{l}\text { Africa region } \\
\text { total }\end{array}$ & 14.80 & 10.90 & 2,357 & 5.60 \\
\hline $\begin{array}{l}\text { Rest of the } \\
\text { world total }\end{array}$ & 85.20 & 31.80 & 420.50 & 94.40 \\
\hline
\end{tabular}

Source: Miniwatts (2010)

The percentage of Africans who use the internet in the globe is $5.60 \%$ as compared to $94.40 \%$ percent in the rest of the world, as shown in Table 1.1. Given that Africa has a population of 14.8 percent of the world's population, this proportion is quite low. Africa has a low internet penetration rate (10.9 percent) compared to the rest of the globe (31.8 percent) (Internet World Statistics, 2012). 
In Kenya, the primary goal of middle-level colleges is to provide students with opportunities to explore practical aptitudes, develop fundamental skills, and gain a technological perspective that will enable them to become better and more informed societal members. The Ministry of Higher Education, Science and Technology has also recommended internet use at post-secondary institutions under the Education Act (Kenya Laws \& Statutes, 2012).

\subsection{Problem Statement}

Many academic institutions, including the Internet infrastructure, are quickly embracing data technology. Many of them are have started including ICTS (Information and Communication Technologies) in their learning programs. Despite the importance of internet usage to kids' academic success, it has a variety of negative consequences. Gaming and social networking are some of the non-academic activities that students use the internet for, causing them to miss class (Singh et al., 2013). Ngoum and Joka (2012) discovered that certain pupils in Johannesburg, South Africa, utilize the internet for recreational rather than instructional objectives, which can lead to lowered academic levels. Charting, downloading, viewing movies online, playing online games, and online buying are among the most popular non-academic activities of the internet among most intermediate-level college students (Akin-Adramola, 2014).

\subsection{Theoretical Framework}

This research employed the Use and Gratification Theory (Liu 2002). The hypothesis was born out of a functionalist approach to mass media communication (Liu, 2002). This theory is concerned with the many ways in which people utilize media and the pleasure they gain from it. It is concerned with what media individuals use, how they are utilized, and what reward pupils expect from their use. The Use and Gratification Theory according to Karimi et al (2020) has given a progressive approach in the early phases of every new communication platform, including newspapers, radio, television, and now the internet. The advent of computer-mediated communication has increased the importance of uses and gratifications.

The applicability of the aforementioned theory is based on the assumption that mass media products serve the audience. In this day, when the internet delivers a wealth of knowledge to society and students, in particular, they have the luxury of selecting whatever information is most useful to them, as well as utilize it for other purposes.

With the broad acceptance of new media, there is a lot of interest in the internet. As noted by Kaye and Johnson (2004), findings from Use and Gratification Studies on Television (UST) have been adapted to internet research. The UST is based on the premise that users have specific reasons and motives for choosing media, and that they purposely choose a message source that best meets their particular requirements. This idea applies to this study's goal of determining how college students utilize the internet for educational or social purposes.

\section{Literature Review}

The following difficulties were identified after a study of the literature: The historical context of internet usage, the purpose of going online by scholars and the effects of constant use of 
the internet on academic performance among institute scholars are all discussed.

\subsection{Historical Perspective of Internet Usage}

The internet has expanded the possibility of library contact beyond the physical library among users, coworkers, and other skillful activities as well as interactions among its users. Several scholars across the world, including Africa, have looked at the usage of online resources (Crocker, 2017). In today's world, higher education institutions encourage students to utilize the internet by requiring new students to have an email address and an internet access account where they may get important school information. For decades, the Internet has advanced to the point where it is now an essential component of many countries' communication and media environments, as well as everyday life, culture, and society (Calixte, 2014). This gradual development has necessitated transfer of knowledge on inventions, changes, actors and continuities not just from a technological standpoint, but from a scientific, social, political, and economic perspective as well.

The internet has not been constituted in the academic literature in the past hence a rise in the number of journal articles and books published in the last decade confirming that Internet history is a growing field in the scholarly world and technology, media, communication and culture study in a variety of settings and institutional contexts (Niels e al, 2017). Studies on the history of the internet have primarily been published in journals on a range of disciplines. These publications rarely publish articles with a clear historical focus becoming a major barrier to the field's progress.

Internet research is a diverse field of study which began in the mid-1990s in the social sciences and humanities. The key emphasis was studying the online Internet and its origin, as well as specific communities like engineers, scientists and the earliest virtual communities that arose, sometimes outside of the Internet, newsgroups especially under the banner of cyberspace and cyber studies. With the emergence of the Internet, the attention shifted to finding appropriate theories and methods for studying it.

\subsection{Purpose of Using the Internet and Academic Performance}

Academic achievement is critical to children's success in school and their transition to the workforce, and internet connectivity plays a critical role. Sumaiyah, Kechik, Saidi, and Chan (2018) conducted a research in Malaysia to assess the efficacy of internet use for scholarly reasons among undergraduate students studying various undergraduate courses. The study focused on the importance of internet use among university students in their academics. Findings showed that pupils' socioeconomic position had both positive and adverse influences on their academic success. The number of times learners spent more than one hour online was influenced by a variety of factors. The reasons for accessing the internet ranged from communication to academic research. Google was ranked top as the search engine commonly used. PubMed was the commonly visited database for academic searches among students. According to the literature reviewed, students felt that the use of the internet enhanced their academic performance.

Yebowaah (2018) examined the usage of the internet and its influence on High School pupils 
in the Wa Metropolis in Ghana. A sample of 314 third-year students was selected and data collected. The researchers used questionaries to collect data which was later analyzed through descriptive statistics, chi-square, and ANOVA. The results suggested that the goal of accessing the internet was educational. According to the study, students' internet accessibility was also shown to have a significant influence on their academic performance. On the other hand, the research found out that there were students whose academic performances was not impacted by the internet. This is because some of the sources needed for them to excel in some disciplines were not available on the internet. Some students were not able to access the internet due to limited internet facilities in the school. As a result, the schools were advised to partner with the concerned government officials and policymakers to enhance internet accessibility among all scholars. This would enhance the academic performance of students in the school. Besides, Mohammed, Muhammad, and Tairu (2017) reported that the internet had some influence on the academic achievement of learners in one of the tertiary learning organizations in one state in Nigeria.

\subsection{Effects of constant use of the Internet on Academic Performance}

The internet is a technology that has become ingrained on regular basis to our daily lives. Its use has surged over years and is now available in places as diverse as homes, workplaces, travel, and schools. Yajun et al. (2014) researched conducted a study in China to ascertain the level of internet addiction among Chinese children. The study examined a national sample that represented Chinese middle school children all over the country and analyzed Internet addiction among different types of Internet users. The findings came from the National Children's Study of China (NCSC), which included 24,013 fourth- through ninth-grade kids from 100 counties across 31 Chinese provinces. Only 54.2 percent of the kids had used the Internet in the previous year. It was found that the prevalence of Internet addiction in the entire population was $6.3 \%$, and $11.7 \%$ among regular internet users. The number of elementary school pupils who were addicted to the Internet (11.5\%) wasn't considerably lower than the rate of students in middle school (11.9\%). According to the study, internet addiction rates were directly proportional to the time spent online. The more time spent online, the higher the rate of addiction. Adolescents who regularly browse in Internet cafés (18.1 percent) and play Internet games had the greatest rate of Internet addicts as far as the location and purpose of internet use was concerned (22.5 percent). The frequency and duration of time spent surfing the Internet each week was found to be positively associated with Internet addiction risk (Mami \& Hatami-Zad, 2014).

Puspita and Rohedi (2018) studied the Effects of Frequency of Internet Use for Students in Indonesia to determine the impact of internet access on academic performance. The study employed a descriptive quantitative approach. The population sample data was evaluated and re-evaluated using statistical methods. The data from a sample of 120 learners demonstrated that frequent Internet use leads to addiction and can create adverse and less supportive behavior in learning endeavors. This perspective was imminent in the study's findings, which found that 82 participants (68.33 percent) answered always and 50 participants (41.67 percent) replied frequently when using the internet for social media; 120 participants (65 participants or 54.17 percent) replied always when using the internet for online games; and 50 
participants (41.67 percent) replied frequently when using the internet for online games.

\section{Methodology}

\subsection{Research Design}

The study used a descriptive research approach. A descriptive study is one in which data is gathered without causing any changes to the environment (i.e. nothing is manipulated). This design was most appropriate because it helped the researcher obtain first-hand information in terms of institutional and human elements impacting security management in sampled public secondary schools. This type of study describe the features of a single person or a group of people (Kothari, 2005). The goal of descriptive survey design is to obtain relevant and exact information on the present condition of phenomena and if feasible, draw accurate general inferences from the facts gathered. It also entails asking consenting participants a series of questions, summarizing their replies with statistical indexes, and then noting down various inferences regarding the population from the sample's replies (Creswell, 2007).

\subsection{Target Population}

Mugenda and Mugenda (1999) asserted that a population is a collection of individual examples of items that share particular observable property. The research targeted college students who rely on the internet most of the time for access to information in their academic pursuits. Students at Nairobi Institute of Business Studies (NIBS), which has 3000 students and located along the Thika superhighway were sampled for the study. Their distribution is shown in the table below.

Table 3. 1: Distribution of Students

\begin{tabular}{ll}
\hline School or department & Number of Students \\
\hline Business studies & 600 \\
Accountancy & 250 \\
Secretarial studies & 150 \\
Community development and social work & 180 \\
Tourism and hospitality & 765 \\
Information and technology & 645 \\
Engineering & 170 \\
Journalism and media studies & 240 \\
\hline Total Population & $\mathbf{3 0 0 0}$
\end{tabular}

Source: (Researcher, 2020)

\subsubsection{Sampling Procedure}

Sampling is the practice of picking a subset of examples to make inferences regarding the complete set (Taherdoost, 2016). The respondents were chosen using stratified, proportional, 
and simple random sampling methods. A stratified sampling methodology was utilized, in which the total target population was split into several clusters and then the ultimate sample was randomly selected equally from the different strata (Fraenkel \& Wallen, 2010). Students were chosen using stratified selection based on the sort of course they were taking and their respective departments. Stratified sampling was used because it assures that no substantial subset of respondents is left out. This implies that a wide range of courses and classes were chosen for this poll to guarantee a comprehensive representation of NIBS' full-time programs. The study sample was chosen from the strata using simple random selection. Departments were initially stratified depending on the courses they provided and then rationally sampled from each of the eight departments. Random sampling was then utilized to pick students using Fisher's Computation table of a sampling method.

\subsubsection{Sample Size}

A sample, according to Hanauer (2004) is made up of a portion or percentage of the entire components or units in a specific population. A sample size of 138 NIBS students was employed in this study, out of a total population of three thousand pupils. Students sampling was used because the population being researched was bulk yet well covered by a sample.

Fisher's algorithm was used to calculate the sample size of the study. Some writers have utilized Fisher's formula to calculate sample size (Jung, 2014).

Calculation of the an adequate sample size (n) for a population $<10,000$ people

Where:

“ $n=\frac{z^{2} p q}{d^{2}}$

$\mathrm{N}=$ population sample size

$\mathrm{p}=$ the proportion of the target population thought to have the characteristics of interest. Measured at 90\% (0.9).

$\mathrm{q}=(1-\mathrm{p})$ i.e. the proportion in the target population not having the characteristics of interest $(1-0.9)=0.1$.

$\mathrm{d}=$ level of significance. The level of significance in this study was 0.05 .

$\mathrm{z}=$ the level of confidence. The level of confidence in this study was measured at $95 \%$.

$n=\frac{(1.96)^{2} \times 0.9 \times 0.1}{(0.05)^{2}}$

\section{$3.84 \times 0.9 \times 0.1$}

0.0025 


\section{$\frac{0.3456}{0.0025}$}

$=138$

The interpretation of the above is that, the study used a sample size of approximately 138 respondents.

\subsubsection{Sample Size Distribution}

The proportionate technique of sample size distribution was employed to calculate the sample size of each department, which was dependent on the students population in each school. After deciding on a sample size of 138 students, the sample was dispersed proportionately across the eight departments. Below are the calculations that were used to determine the sample size distribution for each department's students.

Table 3. 1. Sample Size Distribution for the Students

\begin{tabular}{|c|c|c|}
\hline School or department & Population Size & Sample Size \\
\hline$\underline{\text { B.S }}$ & 600 & 28 \\
\hline Acc & 250 & 11 \\
\hline Secretarial studies & 150 & 7 \\
\hline $\begin{array}{l}\text { Community development /social } \\
\text { work }\end{array}$ & 180 & 8 \\
\hline Tourism and hospitality & 765 & 35 \\
\hline Information and technology & 645 & 30 \\
\hline Engineering & 170 & 8 \\
\hline Journalism and media studies & 240 & 11 \\
\hline Total population & 3000 & 138 \\
\hline
\end{tabular}

\subsection{Data collection Procedures}

This research utilized two types of research instruments: a questionnaire and a document analysis guide.

\subsection{Students Questionnaire}

The study used self-report or self-completion questions to obtain the relevant information from the participants. The questions are well designed to obtain data from the participants.

Questionnaires were distributed to the sampled students to capture their views on internet use and its influence on academic performance. 
The primary rationale for choosing the questionnaire format was because it was simple to analyze Navarro-Rivera and Kosmin (2013; it was known to everyone, and it was also less biased and intrusive than a survey. The questionnaire format was also more practical for this research because it was simple to administer and control. The survey allowed research participants to have in-depth and extensive discussions (Creswell, 2007).

The questionnaire was split into two pieces for this investigation. The first section contained social-economic information about the respondents, while the second section contained questions based on the research objectives to elicit a wide range of responses from the students on the extent to which the purpose of using the internet and frequency of internet access impact the academic performance of students at Nairobi Institute of Business studies.

\subsection{Document Analysis}

The evaluation of chosen textbooks also referred to as archival review of scholarly papers was done in libraries that demonstrate the present condition of students' internet use and its influence on academic performance in medium-level institutions (Arkorful \& Abaidoo, 2015). The research study and arguments were based on a critical review of the available written literature. According to (Mogalakwe, 2006), documentary research is equally as excellent as, if not better than, sociological surveys, in-depth interviews, and participatory observations, and it is also more cost-efficient.

\subsection{Validity of the Research Instruments}

Validity connotes a system's capacity to measure what it claims to measure. Instrument validity, according to (Ibiamke \& Ajekwe, 2017), is the degree to which a given instrument accurately measures what it is supposed to measure. For this study, the investigator conducted a pilot study to assess the applicability of the research instrument to improve construct validity. This provided the content validity projection. The items in the surveys were delivered to the department's supervisor, who assessed the content's relevancy. The final surveys incorporated the suggestions, comments, and recommendations offered.

\subsubsection{Reliability of the Instrument}

According to Harcourt (2019), the term "reliability" connotes a test performed on an instrument to ensure that it consistently measures what it claims to measure. The precision, consistency, and accuracy of the research tool are referred to as reliability. It is a measurement of how well research equipment produces consistent results after several trials. The test-retest method was used during the pilot study to ensure that the questionnaires were reliable. The questionnaires were given to the same group of people on two separate occasions for a week. 


\subsection{Data Collection Procedure}

Data may be collected using a variety of methods and tools. However, as Paradis et al (2016) points out, the choice of any method/tool is contingent on the nature of data being gathered, the amount of time available, the amount of money available, and the number of research assistants. These considerations aid the investigator in determining the data gathering tools and procedures to employ in the investigation. A self-completion questionnaire was the primary data gathering instrument.

\subsection{Data Analysis}

The data regarding the phenomenon interest was collected and analyzed. The process of extracting value from raw data is known as data analysis (Onwuegbuzie \& Combs, 2015). Data on the study was cleaned and sorted before processing and analysis. The objective waw used to assess respective qualitative and quantitative findings. Relevant analysis was carried out at several points during the data gathering procedure and conclusion of the study. Statistical Packages for Social Science were used to code quantitative data. The data was subsequently analyzed and processed using descriptive statistics (SPSS 23). In regards to data presentation, percentages and frequency tables were employed. The frequency counts of various replies given by the respondents were then used to produce information on the respondents who participated in the research, to show the trend of various inferences on variables under investigation. The qualitative data was analyzed for common themes related to students' internet use and its influence on academic achievement in intermediate-level institutions. The investigation focused on the purpose of utilizing the internet and how the frequency of internet access affects students' academic performance in Kiambu County. Reports, textbooks, training manuals, seminar and conference reports, and minutes of reports linked to students' internet use and its influence on academic performance at medium-level institutions were evaluated as part of the document analysis.

\section{Findings, Interpretation and Discussion}

\subsection{General Information}

The study sampled 138 college students from the Nairobi institute of business studies. Out of the 138 College students sampled only 126 questionnaires were returned and filled in. These represented a $91.3 \%$ return rate.

Results from the 126 questionnaires concerning this study were presented as follows.

Table 4 1. Response Rate

\begin{tabular}{llll}
\hline $\begin{array}{l}\text { No } \\
\text { participants }\end{array}$ & of $\mathrm{S.S}$ & Percentage \\
& & Rate of response &
\end{tabular}

138 


\section{Source: (Researcher, 2020)}

The sample group that was administered with a questionnaire by the researcher was 138 and 126 questionnaires were returned representing a $91.3 \%$ responsive rate.

\subsection{Demographic Information}

The researcher felt it was vital to obtain information on the respondents' demographics to provide a logical context for the study findings presented in this chapter. This is because demographic information aids in the avoidance of assumptions during the research. The following is a list of demographic data.

Table 4 2. Response as per School/ Department

\begin{tabular}{|c|c|c|}
\hline School/ Department & No. of Respondents & Percentage \\
\hline Business studies & 66 & 52 \\
\hline Computer science & 8 & 6 \\
\hline $\begin{array}{l}\text { Journalism and mass } \\
\text { studies }\end{array}$ & 12 & 10 \\
\hline Engineering & 10 & 8 \\
\hline $\begin{array}{l}\text { Hospitality and } \\
\text { Tourism }\end{array}$ & 30 & 24 \\
\hline Total & 126 & 100 \\
\hline
\end{tabular}

Source: Research Data, (2020)

According to Table 4.2, business studies attracted 52 percent of responders, followed by hospitality and tourism at 24 percent, journalism and mass communication at $10 \%$, engineering at $8 \%$, and computer science at $6 \%$. Table 4.2 summarizes the departments, as well as the overall number of responses from each department.

\subsubsection{Year of Study}

The year of the study reveals whether the student is in his/her first year or the second year of study. Most middle-level colleges offer training that ranges between one and two years. NIBS colleges offer certificate courses that run for a year while diploma-related courses run for two years. The table below categorizes the participants according to their year of study. 
Table 4 3. Year of Study for the Students

\begin{tabular}{lll}
\hline Year of Study & No. of Respondents & Percentage \\
\hline First & 60 & 48 \\
Second & 66 & 52 \\
\hline Total & $\mathbf{1 2 6}$ & $\mathbf{1 0 0}$ \\
\hline
\end{tabular}

Source: Research Data, (2020)

As shown above, data obtained from the respondents revealed that $52 \%$ of the students were in their second year while $48 \%$ were first years.

\subsection{The Purpose of Using the Internet}

The study examines the purpose of using the internet has an impact on academic performance by the students at Nairobi institute of business studies.

\subsubsection{Reasons for Using the Internet}

Students at the Nairobi Institute of Business Studies were asked what they use the internet for, why they use the internet and the impact of the internet on their academic performance. Individuals gave differing reasons as represented below.

Table 4 4. Purpose of Using the Internet

\begin{tabular}{|c|c|c|}
\hline Remarks & $\begin{array}{l}\text { Number } \\
\text { Respondents }\end{array}$ & Percentage \\
\hline Educational purposes & 39 & 31 \\
\hline $\begin{array}{l}\text { Entertainment /Communication } \\
\text { purposes }\end{array}$ & 87 & 69 \\
\hline Totals & 126 & 100 \\
\hline
\end{tabular}

\section{Source: Research Data, (2020)}

Students utilize the internet for educational purposes. 69 percent of participants utilized the internet for amusement and communication. Therefore it can be concluded that most students in colleges utilized the internet mostly for amusement and communication. It was also discovered that just a small fraction of students (31\%) accessed the internet to do a course or education-related research. The findings match with those of Waithaka et al (2013), who discovered that impactful usage of the internet among college students is extremely low, with just $10 \%$ of students using it for educational reasons and 77.5 percent using it for enjoyment. 


\section{Macrothink Institute ${ }^{\mathrm{TM}}$}

This might be because students can easily be drawn to social media sites to kill boredom during their study time while searching for course-related resources on the internet. This makes it simple for them to lose focus on their studies and become involved in social activities.

\subsection{Use and Frequency of Access to Internet Services}

The study's second goal was to find out the effects of frequent internet access on the academic performance of the students at the Nairobi Institute of Business Studies. The study considered hours spent on the internet per day, internet service access and use of the NIBS electronic learning e-resources, other variable included benefits for using the internet.

\subsubsection{Hours spent Using the Internet (per day)}

The students were asked to self-report the duration of hours per week they spend on the internet. The students were asked to tick in the appropriate box and the findings are presented in Table 4.5.

Table 4 5. Hours Spent on the Internet (Per Week)

\begin{tabular}{lll}
\hline Time in hours & No. of Respondents & $\%$ \\
\hline Less than 2 hours & 24 & 19 \\
$\mathbf{2 - 4}$ hours & 33 & 26 \\
$\mathbf{5 - 7}$ hours & 6 & 5 \\
$\mathbf{8 - 1 0}$ hours & 36 & 29 \\
$\mathbf{1 0}$ hours plus & 27 & 21 \\
\hline Total & $\mathbf{1 2 6}$ & $\mathbf{1 0 0}$ \\
\hline
\end{tabular}

From: Research Data, (2020)

Almost all the participants responded that they do spend more hours on the internet. $29 \%$ of respondents indicated that they browse between $8-10$ hours per day, $26 \%$ revealed that they spend between $2-4$ hours per day, 21\% admitted that they do spend more than 10 hours browsing the internet. $19 \%$ revealed that they spend fewer than 2 hours per day on the internet whereas only $5 \%$ of the respondents spend $5-7$ hours per day browsing the internet.

From the analysis, the students can be classified as either low- users, medium users or heavy users. For an individual student low use of the internet can be defined as spending less than 2 hours on the internet per day. Medium use can be described as spending between 5 - 7 hours browsing per day on the internet. From the data analysis in figure 4.4, it can be argued that college students do spend significant hours browsing the internet. These findings concur with 
Apuke and Iyendo, (2018) whose findings revealed that college students spend considerable time browsing the internet and can thus be referred to as heavier users of the internet.

\subsubsection{Internet Services Access}

The students were asked to reveal the internet services they regularly access to browse the internet. Participants were provided with options to choose from. Among the options provided were; Email, the World Wide Web (www) instant messaging (IM) newspaper group and the other caption.

Table 4 6. Internet Services Accessed

\begin{tabular}{lll}
\hline Services Accessed & No. of Respondents & Percentage \\
\hline E-mails & 36 & 29 \\
World Wide Web & 42 & 33 \\
Instant messaging & 30 & 24 \\
Newsgroup & 12 & 10 \\
Others & 6 & 4 \\
\hline Total & $\mathbf{1 2 6}$ & $\mathbf{1 0 0}$ \\
\hline
\end{tabular}

\section{Retrieved from: Research Data, (2020)}

World Wide Web popularly known as "www" appeared to be the most popular with site visited with a representation of 33\%, emails, and instant messaging followed with a representation of $29 \%$ and $24 \%$ respectively. $10 \%$ of the respondents revealed that they accessed the newsgroup. The other captions which had a representation of only 4\%revealed a variety of internet sites that were also accessed by the respondents. Among the listed ones included; WhatsApp, Telegram, Twitter, Facebook, YouTube, and Hangouts and Myspace. This had a representation of only 4\%. From this study, it can be argued that college students visit a variety of internet sites. The popularity of email could be attributed to the reason that almost everyone who is computer literate is required to have an active email account whereby communication with institutions and peers and lecturers is executed. The findings of this study are in agreement with that of Foen $\mathrm{Ng}$, S et al (2013) whose study findings revealed that the majority of college students use a variety of electronic services.

\subsubsection{Benefits for Using the Internet}

The main aim was to examine whether the students benefited in any way by using the internet services and the findings presented are as follows. 
Table 4 7. Benefits for Using the Internet

\begin{tabular}{|c|c|c|}
\hline Remarks & No. of Respondents & Percentage \\
\hline User friendly & 12 & 10 \\
\hline Time-saving & 40 & 32 \\
\hline More information & 56 & 44 \\
\hline $\begin{array}{l}\text { Reliability } \\
\text { information }\end{array}$ & 18 & 14 \\
\hline Total & 126 & 100 \\
\hline
\end{tabular}

\section{Retrieved from: Research Data, (2020)}

The above table shows that some of the benefits that are associated with internet use. Out of 126 respondents, 12 of the respondents with a representation of $10 \%$ revealed that the internet is user friendly, $40 \%$ of the participants with a representation of $32 \%$ stated that its timesaving, 56 of the participants with a representation of $44 \%$ revealed that it has more information, while 18 of the respondents with a representation of $14 \%$ revealed that the information was reliable to their course work.

It can also be deduced from the findings that various online books, online journals, technical reports and scientific databases are available online with a little subscription which can be beneficial to student's areas of study if wisely and properly utilized. This study report agrees with Scheerder et al (2017) who said that the internet offers numerous advantages in a student's academic life since it allows 24/7 access to worldwide sources of knowledge.

\subsubsection{Device/Gadget used to Access the Internet}

Responding to the item on the devices that the students use to access the internet, the students' responses were varied as presented in Figure 4.5. 


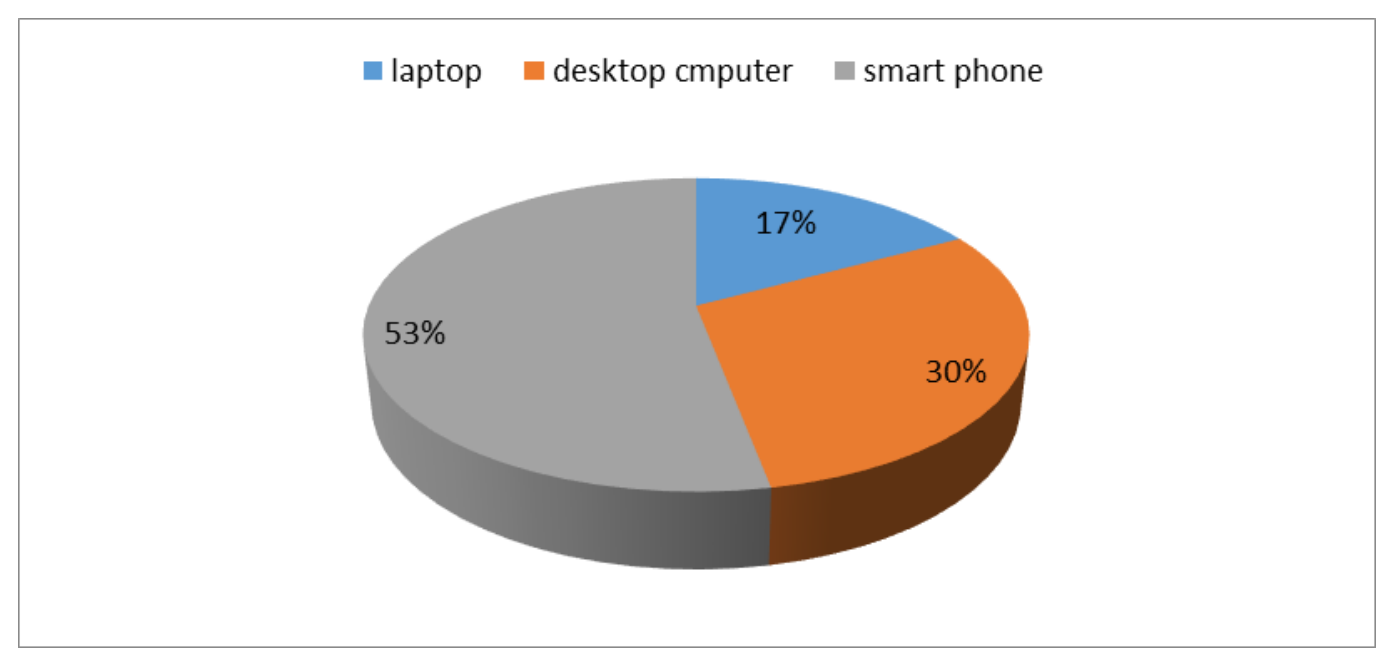

Figure 4. 1. Device used to access the Internet

Source: Research Data, (2020)

As presented in Figure 4.5, slightly more than a half 53\% of the respondents said they use their smartphones to browse and access internet services, $30 \%$ said that they access the internet from their desktops computers while $17 \%$ of the respondents said that they access the internet from their laptops. This shows that most students own a smartphone which they use to access internet services at their own time and convenience. This survey report is in harmony with that of Ramanan and Santharooban, (2019) whose findings revealed that college students use their mobile devices to serve the internet. The 'other' caption provided revealed that some use the "tablet" and 'iPhone' to access internet services.

\subsubsection{Place/ Location Where The Internet Is Accessed}

The students were asked to indicate their preferred choice of internet location that they accessed frequently. Below were the responses. 
Table 4 8. Most Frequently Used Location for Internet Browsing

Remarks No. of Respondents Percentage

University/ College lab

Home

Internet cafe

Hall of residence

Others
37

19

11

59

0
29

15

9

47

0

Total

126

100

\section{Source: Research Data, (2020)}

Among the captions given in the choices were college, home, cybercafé and halls of residents among other captions provided. The above table summarizes the findings where $47 \%$ revealed that they accessed the internet from their halls of residence, $29 \%$ preferred to use the college library, $15 \%$ preferred to browse from their homes and $9 \%$ from the cybercafé. The other options attracted no choices. The possibility of accessing the internet facilities on campus seemed more appealing than the other choices available. This may be attributed to the reason that the facility within the campus is more reliable and functional compared to those located outside and at their homes. This study contradicts the survey by Hanauer (2004) which revealed that $53 \%$ of internet users access it from their homes.

\subsubsection{Websites Used to Access internet Information}

A question on which locations students visit most on the internet was asked and the table below represents the findings.

Table 4 9. Websites Used to Access Information

\begin{tabular}{lll}
\hline Remarks & No. of Respondents & Percentage \\
\hline Google & 96 & 76 \\
Microsoft network & 16 & 13 \\
Online database (i.e. Ebsco) & 14 & 11 \\
Others & 0 & 0 \\
\hline Total & 126 & 100 \\
\hline
\end{tabular}

Obtained from: Research Data, (2020)

As presented above, Google site was the most preferred choice with a representation of $76 \%$, Microsoft network attracted 13\%, while online databases such as Ebsco, Eric and Ask.com and college online publications were very low. The low response may be because the students had 
not started working on their selected project topics at the time of the research. More in-depth online research is required. However, none of the respondents indicated having visited sites other than the stated ones. The study findings collaborate with a study conducted by Karimi, Khodabandelou, Ehsani and Ahmad (2020) which revealed that students relied heavily on Google delivered search sites for current and up-to-date information.

\subsubsection{Accuracy of Information on the Internet for School Work}

Respondents were asked to rate themselves on the accuracy of information from the internet concerning their academic work. A scale ranging from 'never', 'sometimes', and 'always' was provided and the findings were as presented in Figure 4.6.

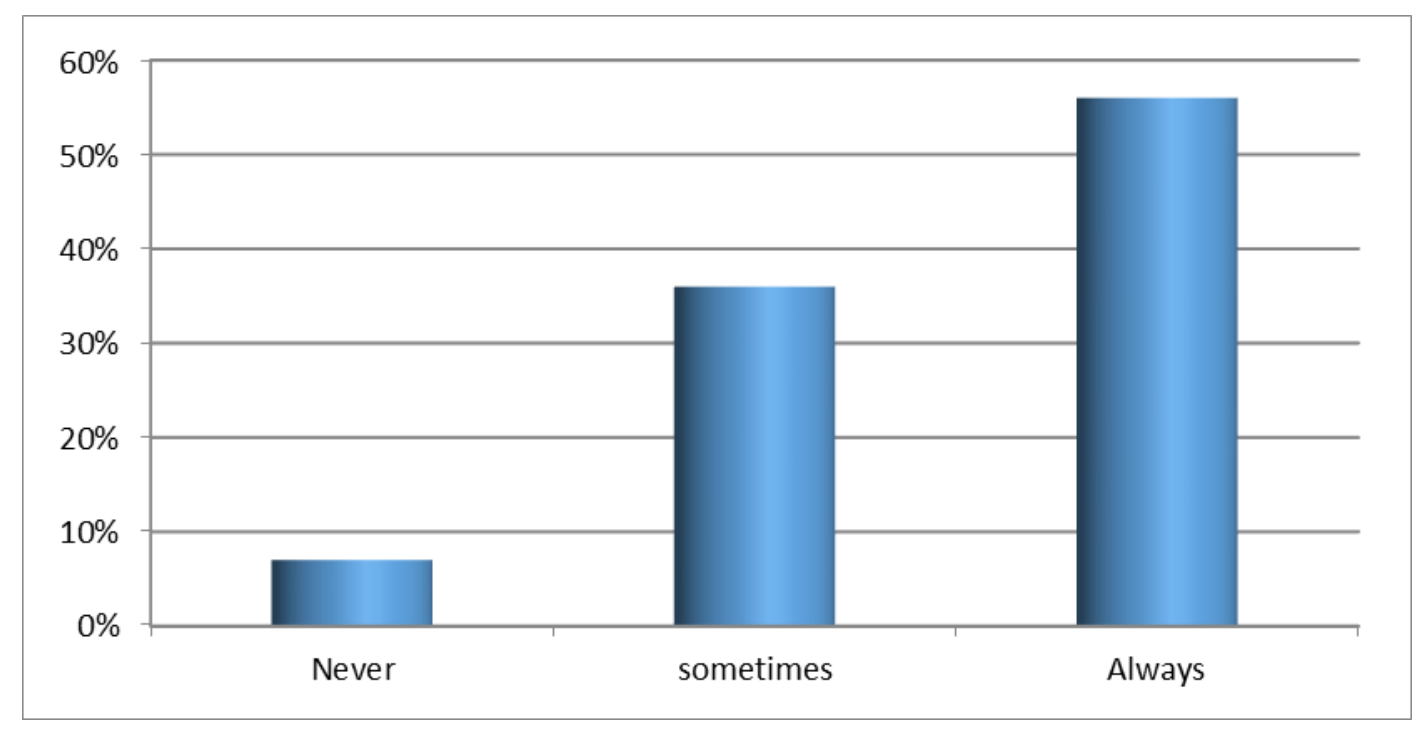

Figure 4. 2. Reliability of Information from the Internet

\section{Source: Research Data, (2020)}

The study revealed that $56 \%$ of the respondents indicated that information on the internet was found accurate to their academic work, $37 \%$ agreed that sometimes the information found on the internet is accurate to their course work whereas $7 \%$ said that the information they found on the internet was never accurate for their academic work. According to the findings of the survey, 56 percent of those who reacted favorably had prior instruction on how to obtain information from the internet. The $7 \%$ who responded negatively could be due to a lack of training on search techniques and the necessary skills required for a person to fully benefit from the internet. Failure to use the right search techniques may give irrelevant results. The $7 \%$ of respondents who indicated that the information found on the internet was never accurate could have been frustrated by poor search techniques. The study findings conquer with that of Bulama et al (2018) who noted that in his study 53\% of the sampled respondents were satisfied with the internet resources. 
4.4.8 Training on the Use of the Internet

The findings are provided in Table 4.9 where the participants were questioned on whether they needed any type of training on search tactics for searching for information on the internet.

Table 4 10. Training

\begin{tabular}{lll}
\hline Remarks & No. of Respondents & \% \\
\hline Yes & 23 & 18 \\
No & 103 & 82 \\
\hline Total & $\mathbf{1 2 6}$ & $\mathbf{1 0 0}$ \\
\hline
\end{tabular}

\section{Source: Research Data, (2020)}

As presented above, the majority, $82 \%$ of those who took part in the research said that they did not require any form of training from the internet. $18 \%$ said that they require some training to enable them to search and locate scholarly information from internet sites with ease. The findings from the study show that the $82 \%$ who indicated that they do not need any kind of training may have had prior training from computer colleges that offer basic computer skills before joining college. The $18 \%$ who opined that they require some kind of training may not have had a chance to learn basic computer skills. This could be the reason why they felt that they needed some training on internet use.

\subsubsection{Other Sources of Information for Academic Purpose}

The students were asked to state the other sources of information for academic purposes.

Table 4 11. Other Sources of Information

\begin{tabular}{lll}
\hline Remarks & No. of Respondents & Percentage \\
\hline Newspapers & 25 & 20 \\
Journals & 34 & 27 \\
Books & 65 & 52 \\
Others & 2 & 1 \\
\hline Total & $\mathbf{1 2 6}$ & $\mathbf{1 0 0}$ \\
\hline
\end{tabular}

Source: Research Data, (2020) 
The analysis of responses as presented in Table 4.10 shows that most of the students used other sources of information for their academic work other than internet sources. Evidence revealed that $52 \%$ of sources of information were from the course books in the library; $20 \%$ indicated that at times they consult education magazines and newspapers that may occasionally have scholarly articles while $27 \%$ revealed that they source for information from journals that are available in their library. The study further revealed that only $1 \%$ sourced information from sources other than the tabulated in table 4.10. It was reported that college students do access internet sources for their education and coursework. They do consult course books to prepare for their assignments, term papers, projects and exams. They also pointed out that print media supplements internet resources.

\section{Summary of the Findings}

The study determined personal variables such as respondents' ages, academic accomplishments, and college departments. A sample group of 138 people was randomly selected and given self-guided questionnaires. The bulk of the respondents in this survey were between the ages of 21 and 24 years old. The number of female students who participated in the survey was higher $(71 \%)$ than male respondents ( 29 percent). In terms of academic qualifications, most of the students were pursuing diploma-related courses whereas only $14 \%$ pursued certificate courses within the various departments that constitute NIBS College. These are business studies, hospitality and tourism, journalism and mass studies, engineering, computer science, community development and social work departments.

\subsection{Purpose of Using the Internet and Academic Performance}

In response to goal one, the survey discovered that the great majority of students $(69 \%)$ believe that they use the internet for enjoyment. Downloading music, movies, playing online games, chatting with friends, and indulging in photoshops were some of the main social kinds of amusement cited by the students. A tiny minority of students, $31 \%$, indicated they utilize the internet for their education or course-related tasks. This group stated that they use the internet to enhance their academic work as well as to finish homework for the numerous courses they are enrolled in.

The study further notes that the students use the internet mainly because of the benefits it adds up to their academic cycle. Among the benefits mentioned by the students were; it provides around-the-clock access to global sources of information, is time-saving, user-friendly, convenient to the users and enables users to conduct in-depth research through cross-referencing leading to links to the topic of the study. The study revealed that the use of the online academic database was very low. The students' reaction may indicate that they were unaware of them or that they had not yet begun working on their chosen project subjects, which would necessitate further in-depth Internet searches.

\subsection{Frequency of access to the Internet and Academic Performance}

The survey discovered that most students spend considerable hours surfing the internet when attempting to determine the frequency of internet access by intermediate-level college students. A majority number of the respondents $29 \%$ agreed that they browse between 8-10 
hours per day. It was noted that the popular internet services accessed by the students were through the World Wide Web popularly known as (www) such as Email; instant messaging and newsgroup. E-mail was the most popular service accessed. This can be argued that anyone who is computer literate has an active Email account. Other services accessed via the internet were such Instant messaging applications as WhatsApp, Telegram, Twitter, Facebook, YouTube, Hangout and Myspace. The study revealed that most of the students do not use the NIBS learning E-resources. The NIBS library and computer lab are small in size and cannot accommodate the big number of enrolled students. The majority of them prefer to visit the nearby Cybercafé: there were several privately owned Cybercafé within the halls of residence where some of them visited for the internet services.

It was also noted that almost every student owns an internet-enabled smartphone. The students only need to buy some data bundles to access the internet. Some owned laptops or tablets from where they could easily access the internet. From the study, approximately 56\% of the students conquered that the information they found from the internet was accurate and relevant to their school work. The small percentage of $(7 \%)$ who said that the information from the internet was inaccurate would be due to the use of the wrong search terms and techniques yielding irrelevant results. It was found that most of the students do not require any teaching on how to search for information from the internet. This can be urged that they had prior training from colleges that offer basic computer literacy skills before joining the college. The study also found out that students sort information from other sources such as education journals, education newspapers and Ebooks that have education literature. This was used to supplement the internet sources which alone are not enough to prepare and complete assignments, term papers, projects and exams.

\subsection{Conclusions}

From the findings, this study makes the following conclusions.

Most middle-level college students spent a greater part of their time using the internet. Therefore, they can be said to be regular consumers of the internet. Due to this, it's very difficult to separate them from the internet which has become a part of their life. The purpose of using the internet among the middle-level students varied across the individuals. Among the notable reasons cited by students were social and educational purposes. The students agreed that they use the internet to download and listen to music, watch video games and play online games. They also use the internet to communicate with their families, peers and friends. The students use the internet for educational purposes. This involves searching online for rich educator information to supplement their coursework.

\subsection{Recommendations}

\section{Recommendations}

i. Based on the fact that not all information found online is useful for educational purposes there is a need for universities and middle-level colleges to regulate or control digital learning content. The purpose is to avoid students drifting into other irreverent sites which distract learning while the student is online. 
ii. Based on the fact that Colleges traditionally small libraries and computer laboratories that cannot accommodate the high number of students enrolled, they should subscribe to electronic databases to enable bonafide students to access the Internet beyond the use of smartphones and use some unscholarly Open Access (OA) information resources.

iii. Based on the fact that some of the students were not aware of some of the online resources available that are rich in educational resources, middle-level colleges should organize and have regular awareness programs aimed at sensitizing students about the various online scientific eBooks, e-Journals, and other emerging relevant sources useful to them alongside the print media.

iv. Based on the student's response that they do spend most their time searching for online education resources, the colleges should organize regular training programmes to train their students on internet search techniques to apply while searching for online information to minimize time spent online searching items of study.

\subsection{Suggestions for Further Research}

i. Further research was recommended in the following areas.

ii. A comparable study can be conducted at lower-level institutions, such as primary or secondary schools, to see if the pattern is comparable to that of middle-level colleges.

iii. A similar research can be conducted in other learning higher institutions. This would be valuable in providing richer insight into how internet resources impact students learning and academic performance.

\section{References}

Akande, S., \& Bamise, O. (2017). The role of School Library in Academic Motivation of Secondary School Students in Osun State, Nigeria. International Journal of Library Science. Scientific \& Academic Publishing, 6(1), 18-27.

Akin-Adaramola, O. S. (2014). Ashesi University College the Internet Usage among Secondary School Students: a case study on Labone Secondary School. Bachelor of Science in Business Administration, Ashesi University College.

Apuke, O. D., \& Iyendo, T. O. (2018). University students' usage of the internet resources for research and learning: forms of access and perceptions of utility. Heliyon, 4(12), e01052. https://doi.org/10.1016/j.heliyon.2018.e01052

Arkorful, V., \& Abaidoo, N. (2015). The role of e-learning, advantages and disadvantages of its adoption in higher education. International Journal of Instructional Technology and Distance Learning, 12(1), 29-42.

Bulama, U. B., Daud, S. M., \& Mahmud, R. (2018). Relationship between Students Satisfaction with the availability of E-resources and Infrastructure, Staff Commitment and Students Involvement in using the E-resources in Colleges. International Journal of 
Academic Research in Business and Social Sciences, 7(14), 614-629. https://doi.org/10.6007/IJARBSS/v7-i14/3693

Calixte, L. (2014). Tim Berners-Lee: “Oui, le Web est ne en France "[Tim Berners-Lee: "Yes, the Web was born in France"]. Challenges. Retrieved from http://www.challenges.fr/high-tech/20140617.CHA5082/tim-berners-lee-oui-le-web-est-ne-e n-france.html.

Chang, H. Y., \& Lin, Z. C. (2003). A study of junior and high scholars playing online games. Instructional Technology and Media, 64, 36-52.

Creswell, J. W. (2007). Qualitative inquiry and research design: choosing among five approaches (3rd ed.). Sage Publications.

Crocker, S. (2017). Tell us about... Internet Histories: Digital Technology. Culture and Society, 1(1-2). https://doi.org/10.1080/24701475.2017.1301132

Ellore, S. B., Niranjan, S., \& Brown, U. (2014). The Influence of Internet Usage on Academic Performance and Face-to-Face Communication. Journal of Psychology and Behavioral Science. 2(2), 163-186.

Foen Ng, S., Syamimi Iliani Che Hassan, N., Hairunnisa Mohammad Nor, N., \& Ain Abdul Malek, N. (2013). The Relationship Between Smartphone Use and Academic Performance: A Case of Students in a Malaysian Tertiary Institution. Malaysian Online Journal of Educational Technology, 5(4), 58-70.

Fraenkel, J. R., \&Wallen, N. E. (2003) How to Design and Evaluate Research in Education, $5^{\text {th }}$ ed. Boston: McGraw Hill.

Hanauer, D. (2004). Internet Use among Community College Students: Implications in Designing Healthcare Interventions. Journal of American College Health, 52(5), 197-202. https://doi.org/10.3200/JACH.52.5.197-202

Harcourt, P. (2019). Construction and Validation Of Chemistry Achievement Test for Senior Secondary Schools In Bayelsa State. 7(2), 106-110.

Ibiamke, A., \& Ajekwe, C. C. M. (2017). On Ensuring Rigour in Accounting Research. International Journal of Academic Research in Accounting, Finance and Management Sciences, 7(3), 157-170. https://doi.org/10.6007/IJARAFMS/v7-i3/3284

Johnson, Y. (2009). The effects of Internet Usage on Educational Performance. Research Report, the University of Witwatersrand.

Jung, S. H. (2014). Stratified Fisher's Exact Test and its Sample Size Calculation. Biometrical Journal. Biometrische Zeitschrift, $\quad 56, \quad 129-140$. https://doi.org/10.1002/bimj.201300048

Karimi, L., Khodabandelou, R., Ehsani, M., \& Ahmad, M. (2020). Applying the Uses and Gratifications Theory to Compare Higher Education Students' Motivation for Using Social Networking Sites: Experiences from Iran, Malaysia, United Kingdom, and South Africa. Contemporary Educational Technology, 5(1), 53-72. https://doi.org/10.30935/cedtech/6115 
Kaye, B. K., \& Johnson, T. J. (2004). A Web for all reasons: Uses and gratifications of Internet components for political information. Telematics and Informatics, 21(3), 197-223. https://doi.org/10.1016/S0736-5853(03)00037-6

Kenya, L., \& Statutes. (2012). Education act chapter 211. Nairobi, Government Printer. Kothari, CR. (2004). Research methodology: methods and techniques (2nd ed.). NewDelhi: Wishwa Prakashan.

Kumar, R., \& Kaur, A. (2005). Internet and its use in the Engineering College of Punjab, India: a case study. Webology, 2(4), 1-18.

Liu, G. Z., \& Hwang, G. (2010). A key step to understanding paradigm shifts in e-learning: towards context-aware ubiquitous learning. Br. J. Educ. Technol., 41, 1. https://doi.org/10.1111/j.1467-8535.2009.00976.x

Mami, S., \&Hatami-Zad, A. (2014). Investigating the effect of Internet Addiction on Social Skills and in High School Students' Achievement. International J. Soc. Sci. \& Education. 4 (Special Issue), 2223-4934.

Mogalakwe, M. (2006). The Use of Documentary Research Methods. African Sociological Review, 10(1), 221-230.

Mohammed, A., Muhammad, N., \&Tairu, S. (2017) Effects of Internet on the Academic Performance of Tertiary Institutions' Students in Niger State, Nigeria, International Journal of Education, Learning and Training, 2(2), 57-69.

Mugenda, O.M. (1999). Research methods in Education, Nairobi: Acts Press.

Navarro-Rivera, J., \& Kosmin, B. A. (2013). Surveys and questionnaires. The Routledge Handbook of Research Methods in the Study of Religion, 395-420. https://doi.org/10.4324/9780203154281-35.

Ngoumandjoka, U. (2012). Correlation between Internet Usage and Academic Performance among University Students. Master of Science, University of the Witwatersrand, Johannesburg. Retrieved from https://www.ncbi.nlm.nih.gov/pmc/articles/PMC3924822/pdf/cyber.2012.0482.pdf.

Niels, B., Gerard, G., Ian, M., \& Valérie, S. (2017) Introduction: Internet histories, Internet Histories, 11(2), 1-7. https://doi.org/10.1080/24701475.2017.1317128

Onwuegbuzie, A. J., \& Combs, J. P. (2015) Emergent Data Analysis Techniques in Mixed Methods Research: a synthesis, Sage handbook of mixed methods in social \& behavioral research. https://doi.org/10.4135/9781506335193.n17

Paradis, E., O’Brien, B., Nimmon, L., Bandiera, G., \& Martimianakis, M. A. T. (2016). Design: Selection of Data Collection Methods. Journal of Graduate Medical Education, 8(2), 263-264. https://doi.org/10.4300/JGME-D-16-00098.1

Puspita, R. H., \& Rohedi, D. (2018). The Impact of Internet Use for Students. IOP Conference Series: Materials Science and Engineering, 306(1). https://doi.org/10.1088/1757-899X/306/1/012106 
Ramanan, T., \& Santharooban, S. (2019). Information Use and Mobile Devices: A Study Amongst Library Users of Selected Medical Faculties in Sri Lanka. Journal of the University Librarians Association of Sri Lanka, 22(1), 23. https://doi.org/10.4038/jula.v22i1.7928

Scheerder, A., van Deursen, A., \& van Dijk, J. (2017). Determinants of Internet skills, uses and outcomes. A systematic review of the second- and third-level digital divide. Telematics and Informatics, 34(8), 1607-1624. https://doi.org/10.1016/j.tele.2017.07.007

Singh, B., Gupta, R., \& Garg, R. (2013). Study of Medical Students and Internet Usage. International Journal of Scientific and Research Publications, 3(5), 47-56.

Siraj, H., Salam, A., Hasan, A., Jin, H., Roslan, B., \& Othman, M. (2015). Internet Usage and Academic Performance: a study in a Malaysian Public University. Japan Health Sciences University \& Japan International Cultural Exchange Foundation. International Medical Journal, 22(2), 83-86.

Sumaiyah, J., Kechik, N., Saidi, S., \& Chan, C. (2018). Usage of Internet for Academic Purposes on University Students' Achievement: A Literature Review. Nursing \& Healthcare International Journal, 2(1), 1-8. https://doi.org/10.23880/NHIJ-16000135

Taherdoost, H. (2016). Sampling Methods in Research Methodology: How to Choose a Sampling Technique for Research. International Journal of Academic Research in Management (IJARM), 5(2), 18-27. https://doi.org/10.2139/ssrn.3205035

Waithaka, M., Onyancha, O. B., \& Ngulube, P. (2013). Internet use among university students in Kenya : a case study of the University of Nairobi Mercy Waithaka, Omwoyo Bosire Onyancha and Patrick Ngulube. Innovation, 49(57), 1-26.

Yajun, L., Xinghui, Z., Furong, L., Qin, Z., \& Yun, W. (2014) Internet Addiction among Elementary and Middle School Students in China: A Nationally Representative Sample Study Cyber psychology, Behavior, and Social Networking, 17(2). Retrieved from https://doi.org/10.1089/cyber.2012.0482

Yebowaah, F. (2018). Internet Use and its Effect on Senior High School Students in Wa Municipality of Ghana. Library Philosophy and Practice (e-journal). Retrieved from https://digitalcommons.unl.edu/cgi/viewcontent.cgi?article=5094\&context=libphilpra

Yesilyurt, E., Basturk, R., Yesilyurt, F., \& Kara, I. (2014). The Effect of Technologica Devices on Student's Academic Success: Evidence from Denizli. Journal of Internet and Application Management, 5(1), 39-47. https://doi.org/10.5505/iuyd.2014.83007

\section{Copyright Disclaimer}

Copyright for this article is retained by the author(s), with first publication rights granted to the journal.

This is an open-access article distributed under the terms and conditions of the Creative Commons Attribution license (http://creativecommons.org/licenses/by/4.0/). 